\title{
La idea de justicia en el pensamiento iusfilosófico portugués contemporáneo
}

\author{
The Idea of Justice in Contemporary Portuguese \\ lusphilosophical Thought
}

\author{
José J. Albert MÁRQueZ \\ Universidad de Córdoba \\ jinalmaj@uco.es
}

RECIBIDO: 04/08/2017 / ACEPTADO: 20/04/2018

\begin{abstract}
Resumen: Frente al tópico de la inexistencia o falta de originalidad del pensamiento jurídico portugués, el artículo trata de evidenciar que existe una línea de continuidad en los temas abordados en la reflexión jurídica portuguesa. La idea de justica es precisamente ese elemento presente de manera continua en el pensamiento jurídico portugués hasta nuestros días. Es destacable hacer notar, además, la escasa literatura jurídica que existe en nuestro país sobre este tema.

Palabras clave: justicia; filosofía jurídica portuguesa; ontología jurídica; derecho; ley.
\end{abstract}

\begin{abstract}
Faced with the topic of non-existence or lack of originality of Portuguese legal thought, the article tries to show that there is a continuity line in the topics addressed in Portuguese legal reflection. The idea of justice is precisely that element present continuously in Portuguese legal thought to the present day. It is noteworthy to note, in addition, the scarce literature that exists in our country on this subject.
\end{abstract}

Keywords: justice; justice; portuguese legal philosophy; legal ontology; law.

\section{INTRODUCCIÓN. El PENSAMIENTO JURÍDICO PORTUGUÉS VISTO DESDE ESPAÑA}

n términos generales, es escasa la literatura jurídico-filosófica que desde
nuestro país ha tenido como objeto de estudio la Filosofía del Derecho
portuguesa. Algún trabajo de Francisco Elías de Tejada ${ }^{1}$ o Tomás Pumar
Ortega ${ }^{2}$ y más recientemente de Juan Antonio García Gómez ${ }^{3}$ (muy documen-

1 Elías de Tejada SpínOla, F., La Tradición portuguesa. Los orígenes (1140-1521), Editorial Actas, Madrid, 1999. Historia de la Literatura Política en las Españas (III tomos), Real Academia de Ciencias Morales y Políticas, Madrid, 1991.

2 Pumar Ortega, T., «Breve exposición del pensamiento iusfilosófico portugués contemporáneo», en Sánchez De La Torre, A. y Hoyo Sierra, I.A. (eds.), Raíces de lo ilícito y razones de licitud, Dykinson, Madrid, 2005, pp. 263-288.

3 Gómez García, J.A., «Visión panorámica de la Filosofía Jurídica Portuguesa Contemporánea: 1880-1992», Boletín de la Facultad de Derecho, UNED, n. ${ }^{\circ} 7$ (1994). 
tado y completo, aunque limitado por la fecha de su publicación hasta comienzos de la última década del pasado siglo) y, en parte, de José Ignacio Lacasta Zabalza suponen notables excepciones.

El hecho del general desconocimiento en nuestro país del panorama iusfilosófico de nuestros vecinos ${ }^{5}$, con quienes hemos compartido durante siglos una historia iusfilosófica común ${ }^{6}$, y algunas peculiaridades que como veremos presenta la filosofía del derecho portuguesa, nos mueven a escribir estas líneas en las que se trata de poner de relieve la importancia que la preocupación por la idea de Justicia tiene en el pensamiento iusfilosófico portugués contemporáneo. Esta preocupación por la Justicia, además, en líneas generales, es perceptible con independencia de la escuela o tendencia de pensamiento de cada autor en particular.

Entenderemos por pensamiento iusfilosófico portugués, a los efectos este trabajo, la reflexión filosófica sobre el derecho en general y la Justicia en particular realizada en Portugal por autores portugueses (excluyendo por tanto a otros, principalmente de lengua portuguesa), y preferentemente (aunque no siempre $^{7}$ ) por profesores de Filosofía del Derecho.

4 Lacasta Zabalza, J.I., Cultura y Gramática del Leviatán Portugués, Universidad de Zaragoza, Secretariado de Prensas Universitarias, Zaragoza, 1988.

5 Con carácter general pueden consultarse: CABRAL DE MONCADA, L., Subsídios para a História da Filosofia do Direito em Portugal (Apresentação de António Braz Teixeira), Imprensa Nacional - Casa da Moeda (INCM), Lisboa 2003; Estudos de Filosofía do Direito e do Estado (2 vols.) (Apresentação de António José de Brito), Imprensa Nacional - Casa da Moeda (INCM), Lisboa 2004; Filosofía do Direito e Do Estado (vol. I, Parte Histórica) Coimbra Editora, reimp., 2. a ed. 1955, Coimbra Editora 2006 (vol. II, Doutrina e Critica) Coimbra Editora, reimp., 1. ${ }^{\text {a }}$ ed., 1966, Coimbra Editora, Coimbra, 2006. TeixeIra, A. B., História da Filosofia do Direito Portuguesa, Caminho, Lisboa, 2005; Caminhos e Figuras da Filosofia do Direito Luso-Brasileira, Associação Académica da Facultade de Direito de Lisboa, Lisboa, 1991. CunHa, P. FerreIRA DA, Temas e Perfis da Filosofia do Direito Luso-Brasileira, Imprensa Nacional - Casa da Moeda (INCM), Lisboa, 2000; «Da Filosofía Jurídica Contemporânea em Portugal», Revista Telemática de Filosofía del Derecho, n. ${ }^{\circ} 6$ (2002/2003); «A Justiça como Virtude e o Direito», Revista Internacional d'Humanitats 13 (2007). CUnHA, P. FERREIRA DA (Org.) Instituções de Direito. I volume. Filosofia e Metodologia do Direito, Almedina, Coimbra, 1998. Galvão DE SousA, J.P., «El Derecho natural en el mundo Lusitano en el siglo XX», en PUY, F. (ed.), El Derecho Natural Hispánico, Actas de las Primeras Fornadas Hispánicas de Derecho Natural, Escelicer, Madrid, 1973, pp. 287-326. Y por todas y más reciente aunque referida al pensamiento filosófico en general, Calafate, P., História do Pensamento Filosófico Português (V vols.) Caminho, Lisboa, 1999 (vol. I, 1999; vol. II, 2001; vol. III, 2001; vol. IV, 2 tomos, 2004; y vol. V, 2 tomos, 2000).

6 Pumar Ortega, T., «Breve exposición...», op. cit., pp. 264-265.

7 Son los casos, en el siglo XX, de pensadores tan importantes como António Brandão, Delfim Santos, Abel Salazar, José Hermano Saraiva, Franz Paul de Almeida Langhans o Eduardo Abranches de Soveral, entre otros muchos, quienes por motivos diversos no ejercieron docencia en facultades de Derecho. 
Valga esta precisión para introducir dos cuestiones preliminares: la primera es que los propios portugueses han creído durante mucho tiempo que no eran un pueblo especialmente dado a «filosofías» ${ }^{8}$; la segunda cuestión es que, a pesar de ello, y como trataremos de probar, la reflexión filosófica sobre el derecho, y particularmente sobre la Justicia es una constante en la historia del pensamiento jurídico lusitano, realizada ya sea de forma implícita o explícita, no solo por académicos (pertenezcan o no estrictamente a la disciplina) sino también por poetas, literatos, filósofos, etc. Lo anterior, unido al hecho de la diversidad de formas en que se plasma esta reflexión iusfilosófica (desde el ensayo al artículo de prensa, pasando por la poesía o el manual universitario ${ }^{9}$ ), ofrecen un panorama particularmente atractivo.

Además, es necesario advertir que al concentrar nuestro objeto de estudio en la Justicia (no en el pensamiento iusfilosófico en general de cada autor), y dadas las limitaciones de extensión de este trabajo, las teorías de algunos de los iusfilósofos que más adelante se citan corren el riesgo de aparecer desfiguradas al presentarse demasiado comprimidas y algo descontextualizadas.

Por último, por cada línea de pensamiento más representativa de las diversas corrientes o escuelas iusfilosóficas portuguesas se ha escogido un autor considerado significativo, siendo evidente que la nómina de filósofos del derecho portugueses que aun tangencialmente han tratado sobre la Justicia es más amplia ${ }^{10}$.

\section{ANTECEDENTES HISTÓRICOS DE LA FILOSOFÍA JURÍDICA PORTUGUESA}

Es un tópico consignar que hasta el último cuarto del siglo XVIII la reflexión iusfilosófica portuguesa se movía entre los márgenes, más o menos es-

8 Cunha, P. Ferreira da, Da Filosofia furídica..., op. cit., p. 21. En sentido análogo, Moncada, L. Cabral DE, Subsídios..., op. cit., p. 19. Salvo indicación en contra, todas las traducciones del portugués son del autor.

9 Cunha, P. Ferreira Da, Temas e Perfis..., op. cit., p. 9.

10 Así, por ejemplo, se pueden citar, sin ánimo exhaustivo, a Delfim Santos (1907-1966), iusfilósofo existencialista, Alvaro Ribeiro (1905-1981) João Baptista Machado (1927-1989) Afonso Rodrigues Queiró (1914-1995) que desde un claro neo-hegelianismo evolucionó hacia el iusnaturalismo, Antonio José de Brito (1927-2013) Augusto Saraiva (1900-1975) Orlando Vitorino (19222003) Franz-Paul de Almeida Langhans (1908-1980) o José Hermano Saraiva (1919-2012). En cualquier caso, los autores de los que se trata en este trabajo son considerados doctrinalmente como los más relevantes, siendo continuamente citados en la literatura científica que aborda la historia y nombres del pensamiento jurídico portugués, literatura que en términos generales es la que se recoge en este artículo. 
trechos, del iusnaturalismo ${ }^{11}$. San Antonio de Lisboa (por muchos conocido como de Padua), Álvaro Pais -en el siglo XIII-, Diogo Lopes Rebelo, Francisco Suárez (que leccionó en Coímbra y está enterrado en Lisboa), Luis de Molina (profesor en Coímbra y Évora) o Manuel de Góis entre muchos otros ${ }^{12}$ se inscriben en esta tradición iusnaturalista que tuvo como núcleo de reflexión la Justicia -en ocasiones reflejada en diversos tratados para la educación de príncipes-, y que vino a ser quebrada con mano férrea por las reformas del Marqués de Pombal. Éste, a la par que reforma los Estatutos de la Universidad de Coímbra (la única del país hasta principios del siglo XX), crea en $1772^{13}$ la cátedra de «Derecho Natural». Esta fue precisamente la puerta de entrada de las nuevas corrientes ilustradas europeas y posteriormente, del krausismo ${ }^{14} \mathrm{y}$ del positivismo sociologista. De hecho, la cátedra, renombrada como de «Filosofía del Derecho» a mediados del XIX, pasó a denominarse desde 1901 «Sociología General y Filosofía del Derecho», siendo definitivamente suprimidos los estudios del Filosofía del Derecho por la reforma universitaria de 1911, fruto primero y temprano de la recién instaurada República ${ }^{15}$ (1910). El mismo año, y no por casualidad, el gobierno republicano acabó con el monopolio universitario de la Alma Mater conimbricense, creando las universidades de Oporto y Lisboa ${ }^{16}$, si bien no dotó a ninguna de ellas de cátedra de Filosofía del Derecho.

Habrá que esperar a $1937^{17}$ (ya instaurado el Estado Novo de António de Oliveira Salazar -a la sazón, catedrático de Economía y Finanzas de la Uni-

11 Por todos, Cabral de Moncada, L., Subsídios..., op. cit., p.19.

12 TeiXeIra, A.B., Historia da Filosofia..., op. cit., p. 44.

13 Es a partir de esta fecha que Cabral de Moncada establece tres periodos en la historia de la Filosofía del Derecho en Portugal: Periodo de iusnaturalismo wolffiano y escolástico (1772-1843); Periodo Kantiano y Krausista (1843-1869), y Periodo de naturalismo cientifista y positivista (1869-1911). Vid., MonCADA, L. CABRal DE, Subsídios..., op. cit., p. 46.

14 Sobre el krausismo portugués, vid., de la profesora de la Universidade do Minho, Calheiros, M.C., A Filosofia furídico-Política do Krausismo Português, Imprensa Nacional - Casa da Moeda (INCM), Lisboa, 2006.

15 Evidentemente, la ideología republicana, fuertemente positivista, propició este giro radical. Vid., v. gr., Gómez García, J.A., «Visión panorámica...», op. cit., p. 282. TeixeIrA, A.B., Historia da Filosofia..., op. cit., p. 170. MonCADA, L. CaBral DE, Subsídios..., op. cit., p. 176.

16 Lacasta Zabalza, J.I., Cultura y Gramática..., op. cit., p. 371; TeiXeIra, A.B., Apresentação a Subsídios..., op. cit., pp.7-16; MonCADA, L. Cabral DE, Subsídios..., op. cit., p. 19 y ss., pp. 283 y ss.

17 No fue ajena a esta situación la publicación en Berlín, en 1938, de la obra de Delfim Santos Situación Valorativa del Positivismo, que supuso una temprana y clara crítica del pensamiento dominante por aquel entonces en Portugal. Becado por el Instituto para a Alta Cultura (a quien dedica el libro), en Viena, Cambridge y Berlín, el que fuera discípulo de N. Hartmann es sin duda uno de los filósofos más importantes del Portugal del siglo XX. Vid., SANTos, D., Situação Valorativa do Positivismo, Berlim [sin editorial, Druck: Dr. Emil Ebering, Berlin NW7, Mittelstr.29] 1938. 
versidad de Coímbra-) para que se restaure en la universidad portuguesa la cátedra de «Filosofía del Derecho», encomendándose en $1945^{18}$, en Coímbra, a Luís Cabral de Moncada ${ }^{19}$, y en Lisboa, paradójicamente a un profesor español, Antonio Truyol Serra ${ }^{20}$.

\section{LA IDEA DE JUSTICIA EN LA FILOSOFÍA JURÍDICA PORTUGUESA}

Como hemos anticipado en líneas anteriores, intentaremos ahora presentar -sin ánimo exahustivo- un apretado panorama del tratamiento recibido por la idea de Justicia en la dogmática iusfilosófica portuguesa contemporánea. Para ello hemos escogido un autor representativo de cada una de las escuelas o corrientes doctrinales que han hecho en mayor o menor medida de la Justicia eje de su reflexión axiológica. Con independencia de otras clasificaciones ${ }^{21}$,

18 LaCASta ZabalZa, J.I., Cultura y Gramática..., op. cit., p. 442.

19 Según escribe Mário Bigotte Chorão, Cabral de Moncada desempeñó un «decisivo papel en la restauración de los estudios filosófico-jurídicos». Vid., M.E., BigOTTE CHORÃO, «Um jusfilósofo português da contemporaneidade (No centenário do Doutor Cabral de Moncada)», en Pessoa Humana, Direito e Politica, Imprensa Nacional - Casa da Moeda (INCM), Lisboa, 2006, p. 556.

20 Truyol fue encargado de la Cátedra de Filosofía del Derecho de la Universidad de Lisboa desde 1950 a 1966. De dicha Universidad el Prof. Truyol fue posteriormente nombrado Doctor honoris causa. Vid., Roldán PanAdero, C., «Antonio Truyol i Serra. Un recuerdo», Thémata. Revista de Filosofía, n. 32 (2004), pp. 377-378.

21 Así, por ejemplo, el propio Cabral de Moncada en páginas publicadas en 1960, nos ofrecía cinco líneas generales del pensamiento filosófico portugués (no del filosófico-jurídico en particular) en el siglo XX: A) Dirección historiográfica e histórico-cultural (representada fundamentalmente por Joaquim de Carvalho). B) Dirección neokantiana (en la cual se incluye expresamente el propio Moncada, junto a Rodrigues Queiró). C) Positivismo lógico o neopositivismo (donde destaca la figura de José H. Saraiva). D) Corriente existencialista (iniciada por Delfim Santos y que culmina António José Brandão), y, finalmente, E) Dirección escolástica neotomista, que para él es aún la dominante en el panorama del pensamiento filosófico portugués. Vid., MonCADA, L. Cabral DE, Subsídios..., op. cit., pp. 285-293.

Por su parte, A.B. Teixeira, al estudiar la historia de la Filosofía del Derecho portuguesa del siglo XX, distingue: I. La reacción antipositivista (Paulo Merêa). II. El derecho y las nuevas formas de positivismo (José Hermano Saraiva, entre otros). III. Del neokantismo a la fenomenología (Cabral de Moncada y Brito Lhamas, entre otros). IV. La perspectiva existencial (António José Brandão y Delfim Santos). V. Rumbos del idealismo y de la dialéctica (Rodrigues Queiró y António José de Brito entre otros). VI. El personalismo jurídico (Mário Bigotte Chorão y Pedro Soarez Martinez). VII. La crítica de la razón jurídica (Baptista Machado, Castanheira Neves y José de Sousa e Brito). Vid., TeixeIrA, A.B., História da Filosofia..., op. cit., pp. 11-12.

Por último, en 2002, Paulo Ferreira da Cunha, en síntesis apretada sobre la filosofía jurídica contemporánea en Portugal se refiere expresamente a Cabral de Moncada, João Baptista Ma- 
trataremos de recoger los principales caminos seguidos cronológicamente por la doctrina desde la segunda mitad del pasado siglo hasta la actualidad, escogiendo para ello reconocidas figuras (muchos de ellos creadores de escuela) de la filosofía del derecho portuguesa. Así, entre los neokantianos abordaremos la obra de Cabral de Moncada; un particular existencialismo vendrá representado por António José Brandão, mientras que la axiología personalista encuentra claro reflejo en la obra de António Castanheira Neves y el realismo jurídico clásico tiene por adalid a Mário Emilio Bigotte Chorão. Desde la historia del pensamiento jurídico, António Braz Teixeira ofrece profundas reflexiones sobre el sentido y el valor de la Justicia y por último, desde la más absoluta contemporaneidad, el sugestivo pensamiento de Paulo Ferreira de Cunha nos provoca en continuo diálogo hacia nuevos postulados críticos con los tópicos iusnaturalistas.

\subsection{La superación del positivismo: Luis Cabral de Moncada (1888-1973)}

El fecundo magisterio de Luis Cabral de Moncada en la cátedra de filosofía del derecho de Coímbra ${ }^{22}$ se extiende hasta hoy a través de sus muchos discípulos ${ }^{23}$. Moncada, considerado como el iniciador de la fase más moderna de la Filosofía jurídica portuguesa ${ }^{24}$, y elemento fundamental de la «reacción antipositivista $\gg^{25}$ que en Portugal encabezó la Universidad de Coímbra, muestra en su obra influencias de Lask, Radbruch, y de la ontología de Hartmann, es por formación un neo kantiano cuya idea de derecho natural recuerda al derecho natural formal de contenido variable ${ }^{26}$ formulada por Stammler.

chado, António Castanheira Neves, Fernando Pinto Bronze, José Manuel Aroso Linhares, José Adelino Maltez, José Lamego, José de Sousa Brito, António Braz Teixeira, António José de Brito y Mário Bigotte Chorão. Vid., CunHa, P. FerreIRA DA, «Da Filosofia Jurídica Contemporânea em Portugal», Revista Telemática de Filosofía del Derecho, n. ${ }^{\circ} 6$ (2002/2003), pp. 21-38.

22 Sus dos obras fundamentales a estos efectos son, Problemas de Filosofia Politica (1963) y Filosofia do Direito e do Estado (2 vols., 1947 y 1966). La obra filosófico jurídica dispersa de Cabral de Moncada ha sido objeto de una nueva edición, con el título Estudos de Filosofia do Direito e do Estado, 2 vols., Imprensa Nacional - Casa da Moeda (INCM), Lisboa, 2004.

23 Entre ellos, Arnaldo de Brito Lhamas, Afonso Rodrigues Queiró, João Baptista Machado, o António Castanheira Neves.

24 Gómez García, J.A., «Visión panorámica...», op. cit., pp. 287.

25 TeixeIra, A.B., Historia da Filosofia..., op. cit., p.171.

26 Moncada, L. Cabral De, Filosofia do Direito e do Estado, vol. II (Doutrina e Critica), cito por la Reimpresión, Coimbra Editora, 2006, p. 302. 
Sin embargo, no siendo positivista, Cabral de Moncada tampoco es iusnaturalista $^{27}$, y entiende el derecho como un deber-ser valioso dirigido a las personalidades libres de los hombres para la realización de sus fines individuales y sociales dentro de un orden objetivo justo ${ }^{28}$. Por otra parte, para Moncada, el derecho busca en la moral el principio o fundamentación de su obligatoriedad, de modo que los valores que lo presiden serían la idea formal de Justicia (entendida como proporción e igualdad, como orden ideal y perfecto, inspirada en el respeto por los fines propios e cada uno y por el fin universal de todos) el respeto por la personalidad y la idea, también formal, de mínimo ético ${ }^{29}$.

El profesor de Coímbra distingue así, en su Filosofía do Direito e do Estado, entre la Justicia como idea (vivencia trascendental necesaria y absoluta) y Justicia como valor (esto es, su vivencia contingente y relativa).

La Justicia como idea sería el orden que consiste en la igual atribución a cada uno, en su ser, y en su hacer, de aquello que específicamente le cabe tener o hacer, cualquiera que sea, en concreto, el criterio para hacer tal atribución ${ }^{30}$. De este modo la Justicia, como idea, abstrayendo su contenido axiológico, sería aquel orden máximo inspirado en el respeto de los fines propios de cada uno y del fin universal de todos, de forma que cada uno y todos, todos y cada uno, puedan ser y permanecer «centros de actos libres, conviviendo y colaborando en la edificación de una unidad superior de sentido y harmonía $\gg^{31}$.

En lo que respecta a la Justicia como valor, Moncada estimaba que si bien era innegable que abstractamente considerada la personalidad constituía la condición y fuente de todos los valores e igualmente que la Justicia era el valor formal más alto o más valioso de todos los contenidos en la idea de derecho, sin embargo excedía a la capacidad de la razón humana determinar a priori, de una forma absoluta y válida para todo los tiempos y lugares, el contenido material de la Justicia y de los demás valores jurídicos. A la razón humana únicamente le resulta posible sugerir o adivinar ese mismo contenido teniendo en cuenta las verdades y los valores jurídicos formales susceptibles de orientar la voluntad del hombre, cabiendo después, en concreto, a la moral reinante

27 Vid., Bigotte Chorão, M.E., «Diálogo com um leitor atento acerca do Doutor Cabral de Moncada», en Pessoa Humana..., op. cit., p. 571 y ss.

28 Moncada, L. Cabral De, Filosofia do Direito..., op. cit., vol. II, p. 44.

29 Ibid., pp. 44 y 264 y ss. Vid., también, Galvão DE SousA, J.P., «El Derecho natural...», op. cit., pp. 315-320.

30 Ibid., p. 43.

31 Ibid., pp. 43-44. 
en cada época y en cada sociedad «a la vida en las diferentes situaciones históricas», llenar el contenido efectivo material del valor Justicia, el cual, por tanto, se presentaría siempre, necesariamente, con un contenido variable en el espacio y en el tiempo ${ }^{32}$.

Y es que, como señalara Teixeira, Cabral de Moncada, si bien dedicó la primera etapa de su vida intelectual a la historia del derecho, ya desde entonces reveló evidentes preocupaciones filosóficas y un entendimiento del mundo jurídico como realidad de naturaleza espiritual-cultural, bien distante de la visión positivista, normativista y sociologista entonces imperante ${ }^{33}$.

Este concepto puramente formal de Justicia fue el que también mantuvo Arnaldo de Brito Lhamas ${ }^{34}$, primer discípulo de Moncada.

\subsection{Perspectiva existencialista: António fosé Brandão (1906-1984)}

Más original y menos conocida es la obra de António José Brandão, cuyo pensamiento jurídico ha sido calificado por António Braz Teixeira de espiritualismo idealista ${ }^{35}$, y por Moncada como existencialista ${ }^{36}$, si bien para Ana Paula

32 Ibid., pp. 290-290. Añade el maestro de Coímbra: «Aceptar tales verdades y valores es como aceptar un cheque en blanco. Esté será después completado por la moral reinante y por la vida en las diferentes situaciones históricas. Ya se ha llamado a esta manera de verlas cosas la concepción de un Derecho natural de contenido variable, y tal concepción, como orientación general, difícilmente podrá ser contestada». Ibid., p. 292.

33 Teixeira, A.B., História da Filosofia..., op. cit., p. 186.

34 Brito Lhamas publicó en 1939 bajo el título O problema da justiça un breve estudio en el que se ocupó de la determinación del concepto formal de Justicia. Para Brito Lhamas, la Justicia se presenta como «una ordenación en la que los fines de una persona están regulados de tal modo, que su realización no implique para otra la imposibilidad de realizar igualmente los suyos», en BRANDÃO, A. J., «Três dissertações de filosofía jurídica», en Vigência e Temporalidade do Direito e outros Ensaios de Filosofia Furidica (2 vols.) Imprensa Nacional - Casa da Moeda (INCM), Lisboa, 2001, vol. II, p. 36.

35 Teixeira, A, B., História da Filosofia ..., op. cit., p. 203. Con él, observa Teixeira, «nuestro pensamiento filosófico-jurídico se libera del formalismo y del relativismo de raíz neo-kantiana y, fundidos en nueva síntesis la lección de la tradición aristotélico-escolástica con los caminos abiertos por el pensamiento fenomenológico-existencial, aporta una visión radicalmente ontológica, que concluye en una axiología que afirma la perennidad y el carácter absoluto de los valores, siendo solo relativo e imperfecto el conocimiento de ellos que alcanza el hombre», Caminhos e Figuras..., op. cit., p. 174. Para Tomás Pumar, Antonio José Brandão constituye «uno de los intelectuales portugueses más importantes del siglo XX». Pumar OrTEGA, T., «Breve exposición...», op. cit., p. 273.

36 Entiende Cabral de Moncada que Brandão se sitúa en el punto de confluencia de la tradición filosófica portuguesa, aristotélico-tomista, con las nuevas directrices de la filosofía europea más 
de Sousa, en materia de Filosofía del Derecho Brandão supera el idealismo neokantiano a partir de una actitud existencial, y su pensamiento se aproxima a la tradición nacional de armonización entre el aristotelismo neo-escolástico de corte tomista y la filosofía alemana ${ }^{37}$.

El autor parte de que la Filosofía del Derecho es, fundamentalmente, ontología jurídica, siendo su primer problema filosófico el de la Justicia en cuanto valor que garantiza la imposición de otro valor: el propio derecho. Las relaciones entre el derecho y la Justicia serán, así, relaciones axiológicas, relaciones entre un valor imponible (el derecho) y un valor que torna tal imposición posible y valiosa (la Justicia).

Las meditaciones sobre la problemática de la Justicia se orientan en la obra de António José Brandão en dos direcciones: de un lado saber si la Justicia pertenece al derecho como principio o como fin último, y, por otra parte, determinar si la esencia de la Justicia es inmanente al derecho, o si por el contrario éste es el valor ético que le da norte, siéndole transcendente ${ }^{38}$. Para el pensador lisboeta, la Justicia está presente en el plano vivencial y especulativo de todas las personas, si bien de forma rudimentaria y pre-intelectual, expresándose en juicios axiológicos, desde la experiencia, y referidos a un deber que implica elementos no racionales. La Justicia se presenta así como un enigma, siendo tarea de la filosofía del derecho encontrar el principio ideal a priori del que ella depende.

Para Brandão, en consecuencia, el derecho es en sí mismo un valor porque posibilita tornar valiosas las realidades que participan de él, «es el que imprime sentido jurídico a los actos y situaciones producidos bajo su regencia» ${ }^{39}$.

reciente, principalmente alemana. Son claramente visibles las influencias, principalmente, de Dilthey, Sheler, Ortega, Husserl, N. Hartmann y Heidegger, así como de la escuela egológica argentina de Cossio. MonCada, L., Cabral DE, Subsidios..., op. cit., pp. 289-290. Para Gómez García, su pensamiento jurídico se encuentra en la línea del de Baptista Machado, al que califica de «ideológico», ya que presenta una determinada idea de Justicia. GómEz GARCía, J.A., «Visión panorámica...», op. cit., p. 301.

37 Sousa, A.P. Loureiro DE, O essencial sobre António fosé Brandão, Imprensa Nacional - Casa da Moeda (INCM), Lisboa, 2008, p. 7.

38 Ibid., p. 63.

39 BRandẽo, A.J., Vigência e Temporalidade do Direito e outros Ensaios de Filosofia Furidica (2 vols.) Imprensa Nacional - Casa da Moeda (INCM), Lisboa, 2001, vol. I, p. 86. Según Moncada, para Brandão el derecho es un elemento constitutivo de un sistema de vigencias propio de cada época histórica. Ese sistema de vigencia (o, como diría Ortega, de «creencias») de que el derecho forma parte, constituye en su unidad esencial una suerte de proyección del espíritu humano sobre la realidad histórica de la cultura, dando así origen a diversas concretizaciones en momentos culturales distintos. MoncadA, L., CABRAL DE, Subsidios..., op. cit., p. 290. 
Sin embargo el fin propio del derecho no debe ser identificado con la Justicia, pues al referirse a ella el derecho lo hace en cuanto norma de acción, que debe ser justa, pero toda vez que la acción se da en la comunidad y se tiene que escoger lo valioso para la vida en conjunto, el derecho atiende al bien común. Esto es, el derecho es un valor que tiene como fin el bien común.

Por otra parte, en el entendimiento de Brandão, la relación entre la Justicia y el derecho no es de dependencia, ligando un ser a la idea que lo torna valioso, sino una relación valorativa de imposición de otro valor. Es decir, la Justicia es el valor moral de la imposición del derecho al hombre ${ }^{40}$. No se entiende como un criterio definidor del derecho pues el derecho es principio creador de la realidad jurídicamente valiosa, y no es indiferente al bien común, dado que este para realizarse debe ser justo. La Justicia es el valor que antecede y orienta la imposición del valor jurídico y, en esa medida, dice como debe ser el derecho y le exige determinado contenido. Ambos, forma y contenido de lo jurídico, le están subordinados.

Por último, para António José Brandão, la Justicia se realiza en la práctica como equidad ${ }^{41}$, que es concebida como una extensión de lo justo, y que perfecciona la Justicia en el caso concreto permitiendo la realización del bien común.

\subsection{La axiología personalista de António Castanheira Neves (n. 1929)}

Como señala Paulo Ferreira da Cunha, en Neves (Catedrático de Filosofía del Derecho y Metodología de la Universidad de Coímbra hasta su jubilación en 1999) la Justicia, más que criterio de validez o validación del derecho, es su principio constitutivo, tanto en una dimensión entitativa (constituyente y ontológica) como en una dimensión cognoscitiva. Por su parte, António Braz Teixeira incluye el pensamiento jurídico de António Castanheira Neves ente los cultores de la axiología personalista ${ }^{42}$.

40 Brandẽo, A.J., Vigência e Temporalidade..., op. cit., vol. I, p. 91. Vid., v. gr., Pumar OrTega, T., «Breve exposición...», op. cit., p. 278, y también, SoUSA, A.P. LOUREIRO DE, «O pensamento filosófico de António José Brandão», Didaskalia, n. ${ }^{\circ}$ XXXI (2001), pp. 117-129, pp. 127-128. Igualmente en ID., O essencial sobre António..., op. cit., p. 66.

41 Sousa, A.P. LoureIro DE, «O pensamento filosófico...», op. cit., p. 67.

42 Teixeira, A. B., História da Filosofia..., op. cit., p. 247. Si bien, como hemos reseñado con anterioridad, lo incluye en un capítulo titulado «La crítica de la razón jurídica», junto a João Baptista Machado y José de Sousa e Brito. 
En la obra del profesor de Coímbra, el derecho es concebido como orden, como principio de validez práctico-axiológico, como idea referida a una realidad histórico-concreta, como una realidad humana referida a personas, que tiene en la Justicia su principio regulativo ${ }^{43}$.

De ahí resulta que el derecho no puede identificarse con la ley, la cual no es más que un instrumento positivo al servicio de una intención axiológica de validez normativa que la sobrepasa. De igual modo, toda vez que el derecho es una intención axiológica de validez normativa y de cumplimiento históricoproblemático, un «deber ser que es», entiende Castanheira Neves que su realización práctica no puede dejar de remitirse a una intencionalidad normativa transpositiva. $\mathrm{Y}$ ese principio normativamente transpositivo es precisamente la Justicia.

Desde unos sólidos fundamentos axiológicos personalistas, Castanheira Neves asienta su visión de la Justicia como suprema axiología de la existencia humana comunitaria y como «la intención y la exigencia, normativamente integrante y dinámica, de reconocimiento de cada uno ante los otros en la coexistencia en un mismo todo construido por todos» ${ }^{44}$, del que resultará no poder comprenderse el sentido del derecho solo en sus objetivaciones histórico-positivas, sino esencialmente en la axiología humana, en la dignidad que implica a su vez la libertad y la igualdad ${ }^{45}$.

Por otra parte, para Neves, la Justicia es el principio regulativo del derecho, lo que hace que sea derecho, y en consecuencia solo el derecho justo obliga y es verdaderamente derecho. Pero la Justicia no es, sin embargo, solo el principio entitativo del derecho, aquel que lo fundamenta y le da el ser, es también en Castanheira Neves su principio cognitivo, pues es ella y no la verdad el valor último del pensamiento jurídico ${ }^{46}$.

Consecuencia de lo anterior, es que para Castanheira Neves el derecho natural no puede concebirse como tradicionalmente hace el iusnaturalismo -al menos según lo concibe el autor-, como un dato objetivo, teóricamente investigable y expresivo de un sistema de principios o de normas trascendentes; antes más bien, debe entenderse como una intención normativa, un trascender

43 Ibid., p. 246.

44 Neves, A. CastanheIra, «Justiça e Direito», en Digesta, Escritos acerca do Direito, do Pensamento furídico, da sua Metodologia e Outros (Reimpressão), Coimbra Editoria, Coimbra, 2011, vol. I, pp. 241-286.

45 GÓMEZ García, J.A., «Visión panorámica...», op. cit., p. 302.

46 TeiXeira, A. B. História da Filosofia..., op. cit., p. 247. 
en acto intencional normativo a partir y por referencia a la realidad histórica ${ }^{47}$. En suma, como observa Ferreira da Cunha, es el derecho natural un continuo construirse y rehacerse, una verdadera constant et perpetua voluntas ${ }^{48}$.

\subsection{Realismo jurídico clásico: Mário E. Bigotte Chorão (n. 1931)}

Calificado por su compatriotas como el máximo exponente portugués del iusnaturalismo clásico ${ }^{49}$, el profesor -hoy jubilado- de la Universidad Católica de Lisboa prefiere definir su pensamiento jurídico como «realismo jurídico clásico ${ }^{50}$, abierto, por su naturaleza, a todas las aportaciones susceptibles de desvelar el verdadero ser y sentido del derecho, entre ellas el personalismo ${ }^{51}$.

En una formulación comprensiva, define el derecho como «la ordenación de la vida social según la Justicia» ${ }^{52}$, que se obtiene básicamente con la atribución a cada cual de aquello que es suyo ${ }^{53}$, reflejando así la convicción de que existe una relación necesaria y esencial entre el derecho y la Justicia.

47 Neves, A. Castanheira, A Crise Actual da Filosofía do Direito no Contexto da Crise Global da Filosofia, Coimbra Editora, Coimbra, 2003, pp. 40-52.

48 CunHa, P. FERreira DA, «Da Filosofia Jurídica...», op. cit., p. 28.

49 Teixeira, A. B. História da Filosofia..., op. cit., p. 235. Cunha, P. Ferreira DA, «Da Filosofia Jurídica...», op. cit., p. 36. En sentido análogo, Aguilar DE OliveIRA, J., «O neotomismo de Mário Bigotte Chorão», Revista Estudos Filosóficos, n. ${ }^{\circ}$ 14/2015, versão eletrônica, UFSJ, São João de Rei, pp.161-173. Accesible en <http://www.ufsj.edu.br/revistaestudosfilosoficos> [consulta: $13 / 05 / 2017]$.

50 Bigotte Chorão, M.E., Introdução ao Direito, vol. I, O Conceito de Direito, p. 12. El profesor lisboeta manifiesta influencias confesadas de la que él califica como «Escuela de Navarra» representada por Javier Hervada, Sancho Izquierdo o Martínez Doral, así como de los autores por ella influidos en Argentina (Carlos Massini, Rodolfo Vigo), en Prólogo, de Temas Fundamentais de Direito, op. cit., p. 15.

51 Vid., v.gr. BigotTe Chorão, M.E., «Nótula sobre a fundamentação dos direitos humanos», en Cunha, P. Ferreira Da (ed.), Direitos Humanos. Teorias e Práticas, Almedina, Coimbra, 2003 , pp. 77-97. Del mismo modo, el Prof. Bigotte Chorão extiende su concepto clásico del derecho a nuevas realidades, vid., «Bioética, Biodireito e Biopolítica (Para uma nova cultura da vida)», en Cunha, P. Ferreira Da (Org.) Instituções de Direito. I volume. Filosofia e Metodologia do Direito, Almedina, Coimbra, 1998, pp. 65-76. Vid., también, BigotTe Chorão, M.E., Pessoa Humana, Direito e Politica, Imprensa Nacional - Casa da Moeda (INCM), Lisboa, 2006.

52 Bigotte Chorão, M.E., Introdução ao Direito..., op. cit., p. 55. De modo parecido en sus Temas fundamentais do Direito, define el derecho como «ordenación de la convivencia humana según la Justicia», op. cit., p. 81. Este concepto de juridicidad, imbuido de la idea de Justicia, lo extiende Bigotte Chorão a su concepto de Estado, vid., Introdução ao Direito..., op. cit., p. 212.

53 Bigotte Chorão, M.E., Temas fundamentais do Direito, op. cit., p. 34. Especialmente el capítulo II, «Justiça», pp. 65 a 83. 
Escribe Teixeira que de aquel concepto de derecho se deduce, por un lado, que la Justicia es en la obra de Bigotte Chorão el fin del derecho o su valor esencial, y, por otro, que el fundamento de éste se encuentra en la naturaleza humana ${ }^{54}$.

Considerada como virtud, la Justicia es definida por el Prof. Bigotte Chorão como la «virtud cardinal que consiste en la disposición de la voluntad de atribuir a cada uno su derecho» ${ }^{55}$. Pero en sentido jurídico, Bigotte estima que la Justicia, elemento constitutivo intrínseco del derecho, es el principio, el fin y el valor fundamental especificador del orden jurídico ${ }^{56}, \mathrm{y}$ esa relación se concreta históricamente en el pensamiento aristotélico, tomista, y en la experiencia del derecho romano. Así, para Mário Emílio Forte Bigotte Chorão, la Justicia se funda en la virtud de la prudencia, pero la razón profunda por la cual algo se debe a un hombre como derecho, es su propia naturaleza humana, su condición de persona, o, más radicalmente: el fundamento absoluto del derecho y del deber de Justicia está en la persona humana como criatura divina ${ }^{57}$.

Cuestión distinta es que, sin embargo, el orden jurídico no alcanza de hecho la realización plena de la Justicia como virtud, sino tan solo consigue un iustum imperfectum, constituyendo así, propiamente, un orden según una cierta o relativa Justicia ${ }^{58}$. Pero no por ello deja el derecho de tener su base en una exigencia ética de Justicia, cuyo sentido se aclara fundamentalmente a la luz de la doctrina de la virtud de la Justicia.

En suma, la tradición del realismo clásico presenta para Bigotte Chorão el derecho como lo justo (y equitativo), de origen natural y positivo, ve en el orden jurídico un orden de Justicia, y concibe la jurisprudencia como saber práctico del jurista, ciencia y arte de lo justo (y equitativo). La realización de la Justicia, de la que depende la paz, es, a su vez, considerada parte integrante e importante del bien común de la sociedad y, por tanto, contribución indispensable para la vida buena (bene vivere) de las personas que la constituyen ${ }^{59}$.

54 TeiXeIra, A. B., História da Filosofia..., op. cit., p. 235.

55 Bigotte Chorão, M.E., Temas fundamentais..., op. cit., p. 72.

56 ID., Introdução..., op. cit., p. 75.

57 ID., Temas fundamentais..., op. cit., p. 76.

58 ID., Introdução..., op. cit., p. 84.

59 ID., «A Justiça, segundo a tradição do realismo jurídico clássico», en Pessoa Humana..., op. cit., p. 69. 


\subsection{Sentido y Valor de la fusticia en António Braz Teixeira (n. 1936)}

Especialmente dedicado al estudio de la historia del pensamiento jurídico en lengua portuguesa, para el pensador lisboeta el derecho es una realidad cultural ${ }^{60}$, una creación humana referida a valores y destinada a darles efectividad, un orden regulador de la conducta social del hombre, que trata de ordenarla justamente. En consecuencia, la Justicia es ese principio, valor o ideal, que constituye la razón de ser o la razón suficiente del derecho.

De ahí surge la consideración del carácter incontenible y perpetuamente auto-superador de la Justicia, que no es susceptible de ser inmanentizada (ni cristalizada) en definiciones o conceptos, sino que más bien se muestra contraria a su captación racional lógico-deductiva, y siempre de algún modo «decaída» (e imperfecta) desde el momento en que queda fijada en los textos legales. Al contrario, según siempre Teixeira, la Justicia se puede intuir anímicamente, está construida a base de experiencias por el juicio axiológico.

En términos generales, para António Braz Teixeira, la problemática filosófica de la Justicia es, simultáneamente, ontológica, gnoseológica, y metafísica ${ }^{61}$.

a) En la consideración del problema ontológico de la Justicia, ésta puede ser considerada desde un punto de vista subjetivo (como virtud individual), o desde un punto de vista objetivo (como valor, principio o ideal). En el sentido objetivo, que es el que interesa en esta sede, el principio o idea de Justicia, en su noción tradicional (la que obliga a dar a cada uno lo que le es debido) implica, según el autor, determinadas relaciones con el derecho, con la igualdad y con la equidad ${ }^{62}$. Veámoslas:

- Con relación al derecho, la Justicia señala lo radical y esencialmente concreto, en oposición a la generalidad y a la abstracción propia de la ley positiva o hasta del derecho natural. Determinar que es «lo suyo»a lo que la Justicia se refiere es más complejo. Si desde el punto de vista

60 TeiXeIra, A.B., «Experiência jurídica e ontología do Direito» en Nómos. Revista Portuguesa de Filosofia do Direito e do Estado, n. ${ }^{\circ}$ 3-4 (1987), pp.24-37, cita a las pp. 29-30. Sus lecciones universitarias se editaron posteriormente bajo el sugestivo título de «Sentido y Valor del Derecho». Vid., TeIXEIRA, A.B., Sentido e Valor do Direito. Introdução à Filosofia furídica, Imprensa Nacional Casa da Moeda (INCM), Lisboa, 1990.

61 TeixeIra, A.B., Sentido e Valor..., op. cit., p.163. Señala el autor que a la Filosofía del Derecho solo interesa la Justicia en su sentido objetivo (como valor, principio o ideal) y no subjetivo (como virtud), ibid., p. 183. Vid., también, CunHA, P. FERreira DA, «A Justiça como Virtude...», op. cit., pp. 34-35.

62 TeixeIra, A.B., Sentido e Valor..., op. cit., p.183. 
de la ética, lo que le es debido a cada uno puede ser lo establecido de acuerdo con la ley o con el derecho (ya que la virtud del hombre justo será antes que nada, respetar el derecho y sus preceptos, que tienen en sí una presunción de validez, siendo, como tal o en esa medida, expresión o manifestación de la Justicia), para el iusfilósofo tal respuesta es inadecuada, porque, para él, la relación entre el derecho y la Justicia es diversa, toda vez que aquel nunca podrá ser criterio de ésta.

En efecto, si la Justicia es el valor, el principio o ideal que da sentido axiológico al derecho, si es su razón de ser y de valer, o su razón suficiente, es el derecho el que debe contrastarse con la Justicia, el que debe ser juzgado en función de su conformidad con ella. De este modo, «lo suyo» de cada uno, lo que le es debido, no puede determinarse ni definirse a partir del propio orden jurídico positivo.

Ahora bien, «lo suyo», en este sentido, debe ser entendido según António Braz Teixeira en un sentido ontológico radical ${ }^{63}$ como aquello de que cada uno dispone o debe disponer para ser él mismo en cuanto persona distinta de todas las demás personas ${ }^{64}$, dotada de un destino individual y de un proyecto vital o existencial. De este modo, si «lo suyo» de cada cual no debe identificarse con la conformidad con la ley, no puede tampoco restringirse a los bienes exteriores o materiales y a su reparto, consistiendo antes de ello en la libertad de cada uno para ser él mismo y poder realizarse como persona. Así la Justicia es, por encima y antes de todo, libertad, que implica respeto por la libre personalidad de cada uno.

- Las relaciones entre la Justicia y la igualdad se conectan en la idea de que la igualdad puede ser y tiende a ser el criterio de la Justicia legal o de la Justicia que se expresa en la ley, pero nunca puede ser el fundamento de la Justicia en cuanto valor, principio o ideal.

- Por último, y en consecuencia, pierde sentido la distinción clásica entre Justicia, entendida como conformidad con la ley, y equidad, concebida como correlación de la generalidad de la ley para algún caso concreto, pues, como sostiene Teixeira, la verdadera Justicia es siempre equidad ${ }^{65}$.

63 Ibid., p.184.

64 TeixeIra, A.B., «Problemática e Sentido da Filosofia do Direito», en CunHa, P. FerreIRA DA (org.) Instituções de Direito. I volume. Filosofia e Metodologia do Direito, Almedina, Coimbra, 1998, p. 148.

65 TeixeIra, A.B., Sentido e Valor do Direito..., op. cit, p.187. 
b) En lo que toca a la gnoseología de la Justicia, ésta no es susceptible de ser definida o deducida genérica y abstractamente por la razón, sino que solo puede ser intuida en el caso concreto, mediante la emoción o sentimiento de evaluación, o sentimiento moral o de Justicia, del cual con todo, es posible dar razón pues posee su verdad que goza de la validez de la experiencia inmediata y de la vivencia de los valores. El juicio sobre la Justicia de un caso concreto, es un juicio axiológico y no un juicio lógico, es pues un juicio de experiencia en el que intervienen decisivamente elementos no racionales ${ }^{66}$.

c) Respecto al fundamento, o metafísica de la Justicia, estima el profesor de Lisboa que éste es un problema que trasciende a la propia Filosofía del Derecho implicando una visión metafísica general sobre problemas esenciales como la idea de Dios, la realidad del mal, o el fundamento ontológico de la libertad ${ }^{67}$.

En cualquier caso para Teixeira la Justicia es un insustancial que no depende de nada pero del que, en el mundo jurídico, todo depende ${ }^{68}$. No puede ser pensada como algo substancial o entitativo, pues antes que nada se revela por su negación o ausencia, por la injusticia. Lo verdaderamente real es la injusticia ${ }^{69}$. Además de la insubstancialidad, para Teixeira son caracteres esenciales de la Justicia la alteridad y la proporcionalidad, lo que conduce al autor a mantener que, desde el punto de vista de la Justicia, es quizás más importante la aplicación de la ley, que la propia ley.

\subsection{La «clásica heterodoxia» de Paulo Ferreira da Cunha: repensando el Derecho Natural sobre la idea de fusticia}

Paulo Ferreira da Cunha (n. 1959) catedrático de Filosofía del Derecho de la Universidad de Oporto es en la actualidad, a mi juicio, la figura más original del pensamiento jurídico portugués. Doctor en Derecho por la Universidad de Paris II bajo la tutela de Michel Villey y Doctor en Derecho por la Universidad de Coímbra (su Alma Mater), en este caso en Derecho

\footnotetext{
66 Ibid., p. 191.

67 Ibid., pp. 192-193.

68 Ibid., p. 187.

69 Ibidem.
} 
Constitucional, ha publicado hasta ahora más de 90 libros y unos 600 artículos en 12 lenguas.

Ferreira da Cunha se ubica intelectualmente en un iusnaturalismo realista inspirado en Villey, Aristóteles y Tomás de Aquino, con una fuerte preocupación en la Justicia social como valor o principio ${ }^{70}$, que abarca, según Virginia Black «lo que podríamos llamar Justicia distributiva, que implica manipular los recursos materiales de una economía productiva para, en teoría, igualar a los individuos» ${ }^{71}$. En este plano, señala el Prof. Cunha, es fundamentalmente donde necesitamos al derecho natural, entendido como vigilante jurídico del poder, y como puente entre el Derecho y la Moral ${ }^{72}$. Para el autor portuense, Justicia, Libertad y Amor ${ }^{73}$ constituyen la gran trilogía jurídica, si bien reconoce que elaborar una teoría de la Justicia es algo muy serio que requiere rigor teórico y responsabilidad ${ }^{74}$, sin olvidar tampoco que en Derecho nada es unívoco, lineal, fácil, porque el Derecho es un producto humano, fruto de los hombres y hecho para los hombres, que además está basado en un ideal que lo trasciende: la Justicia ${ }^{75}$.

En su reciente libro Rethinking Natural Law, Cunha apunta a la construcción dogmática de lo que en mi opinión podría denominarse una «teoría pura del derecho natural», descontaminando (mediante un proceso de-constructivo) de factores políticos, religiosos e ideológicos la idea tópica del derecho natural. Propone así un Derecho natural racional unificado ${ }^{76}$ (unión del clásico y

70 Cunha, P. Ferreira Da, Filosofía do Direito, Almedina, Coimbra, 2006, p. 713. En contra, por ejemplo, Antonio Braz Teixeira, que estima que «la llamada fusticia social, no es más que una forma de Justicia distributiva, pero de forma minorada e imperfecta, por reducir 'lo suyo' o 'lo propio' de cada uno a la posesión de bienes materiales y limitar la Justicia a la respectiva repartición de tales bienes, a la cual sacrifica, en no pocas ocasiones, la propia libertad de creación libre de esos mismos bienes», TeixeIrA, A.B., Sentido e Valor..., op. cit., p. 190. En sentido análogo, Bigotte Chorão, M.E., Introdução ao Direto..., op. cit., p. 79 (en cuanto virtud social) y (con relación a la Justicia objetiva) p. 84.

71 Black, V., Preface, in Cunha, P. FerreIra DA, Rethinking Natural Law, SpringerBriefs in Law, London, 2013, Preface, X.

72 CunHa, P. FERreIRA DA, Rethinking Natural Law..., op. cit., pp. 10 y 11.

73 ID., «Uma concepção preliminar do Direito e algumas noções básicas», en ID. (org.) Instituções de Direito..., op. cit., p.17.

74 ID., «Direito Natural e Teoria da Justiça. Deontologia, Terminologia e Sistematização», Derecho y Opinión, n. ${ }^{\circ} 40$ (1990), pp. 13-52.

75 ID., «A Tópica das Fontes», en ID. (org.), Instituções de Direito..., op. cit., p. 357.

76 Las tesis de Strauss o Villey al respecto, al confrontar directamente el realismo jurídico con el iusracionalismo no parecen acertadas para Paulo Cunha. Con relación a ello escribe: «No creemos que se pueda decir, simplemente, que se trate de un mero anuncio [el iusraciona- 
el moderno) en diálogo continuo y fluido con el derecho positivo («un mundo jurídico perfecto no es uno donde una teoría gana y otra pierde, sino uno donde una teoría siempre demanda de la otra perfeccionarse a sí misma» ${ }^{77}$ ) la literatura, la teoría económica y las modernas teorías de la Justicia. Un Derecho natural que es además concebido principalmente como un método ${ }^{78}$, «como si la dialéctica pudiera ser la metodología específica del Derecho» ${ }^{79}$, una búsqueda continua en la naturaleza de las cosas y especialmente en la naturaleza del ser humano ${ }^{80}$. En suma, una búsqueda de lo justo que se deberá realizar por las vías de la dialéctica ${ }^{81}$.

Para el Prof. Ferreira da Cunha, la Filosofía del Derecho debe ser una Filosofía de la Justicia ${ }^{82}$, siendo necesaria la construcción dogmática de una Teoría de la Justicia seria y responsable ${ }^{83}$ pues la Justicia (principio, valor, fin y virtud ${ }^{84}$ ) es todavía uno de los grandes valores de la humanidad, y el mayor valor del mundo legal, resultando imprescindible para el derecho. La idea de Justicia es pues la fuerza motora del Derecho Natura ${ }^{85}$. Pero, acto seguido, manifiesta el autor que «preferimos no saber lo que exactamente es la Justicia, sino perseguir implacablemente la búsqueda. Además, la Justicia es una constante y perpetua voluntad (constans et perpetua voluntas), y no un refugio de paz que alcanzar» ${ }^{86}$.

lismo luso-brasileño] del positivismo. En muchos aspectos es un realismo de peluca empolvada, en su versión decadente. En otros, anuncia vientos de despotismo ilustrado. En otros, todavía, canta himnos de libertad. Es sobre todo uno de aquellos fenómenos que no se pueden despreciar, ni catalogar apresuradamente, antes de un atento examen de muchas fuentes». CunHa, P. Ferreira Da, Filosofia do Direito..., op. cit., p. 325. También en «Jusnaturalismo e Jushumanismo. O desafio da Declaração dos Direitos do Homem e do Cidadão de 1798», en Cunha, P. Ferreira Da (ed.) Direitos Humanos. Teorias e Práticas, op. cit., pp. 35 52. En contra, por ejemplo, Mário E. BigotTe Chorão, en «Algunas cuestiones acerca del Derecho natural en la Cultura Portuguesa», en Ayuso, M. (ed.), El Derecho natural Hispánico, Actas de las II Fornadas Hispánicas de Derecho Natural, Cajasur Publicaciones, Córdoba, 2001, pp. 599 y 600 .

77 CunHa, P. Ferreira Da, Rethinking Natural Law..., op. cit., p. 54.

78 Ibid., p. 30.

79 Ibid., p. 40.

80 Ibid., p. 43.

81 Cunha, P. Ferreira Da, Filosofia do Direito..., op. cit., p. 564.

82 Ibid., pp. 149-150. En análogo sentido lo afirmaba también el citado autor en otra sede; vid., ID., Lições Preliminares de Filosofia do Direito (2. ${ }^{a}$ ed., revista e actualizada), Almedina, Coimbra, pp.143 y 144.

83 ID., «Direito Natural e Teoria da Justiça...», op. cit., pp.15 y ss.

84 ID., Filosofia do Direito..., op. cit., p. 712.

85 Ibid., p. 303.

86 Cunha, P. FerreIra DA, Rethinking Natural Law..., op. cit., p. 54. 
Así, el jurista ha de buscar la Justicia «no como un mero policía o guarda nocturno que protege a los que mucho tienen de los que nada poseen ${ }^{87}$. La Justicia, en definitiva, es el fin o el objetivo al que tiende el ejercicio del derecho (como arte de la Justicia) ${ }^{88}$. Justicia y derecho son inseparables, diríase que lo son en el principio, en el medio y en el fin ${ }^{89}$, y el resto, apuntilla el autor, son glosas, o distanciamientos, contradicciones o disputas ${ }^{90}$.

Paulo Cunha califica su propio pensamiento jurídico como «neo-Iusnaturalismo crítico» ${ }^{91}$, pero de inmediato indica que lo que importa mucho más que las etiquetas, siempre sujetas a controversia y malentendidos, es la fidelidad al espíritu de la Justicia. Esto es lo que cuenta, incluso más hoy día, en tiempos de profunda y prolongada crisis, cuando el mundo necesita un sentido que la Justicia podría ayudar a encontrar. Esto, sin embargo, requiere, en palabras del propio Prof. Ferreira da Cunha, que la Justicia se encuentre a sí misma, como el antiguo y el nuevo Derecho natural han hecho» ${ }^{92}$.

87 Cunha, P. Ferreira DA, «Libertar o Direito...», Furismat, n. ${ }^{\circ} 5$ (2014) pp. 143-155, p. 149.

88 ID., Filosofia do Direito..., op. cit., pp. 293-295. CunHA, P. FERreIRA DA, Rethinking Natural Law..., op. cit., p. 43. Y también, al abordar el problema de la ontofenomenología en su Filosofia do Direito, afirma. «Saber que la Justicia es la constante y perpetua voluntad de dar lo suyo a su dueño es más perenne, es más importante, que haber supuesto o presuntamente encontrado la fórmula para hacer la referida atribución. Lo que parece más razonable es que cada tiempo y lugar busca formas cada vez más justas de hacer Justicia, aunque la Justicia no pueda ser encerrada en una fórmula definitiva, Está en camino, en construcción. Por eso es constante y perpetua voluntad», ID., Filosofia do Direito..., op. cit., p. 413.

89 Cunha, P. Ferreira Da y Dip, R. MArques, Propedêutica furidica: uma perspectiva iusnaturalista, Millenium Editora, Campinas, 2001, p. 122.

90 CunHa, P. Ferreira DA, «A Justiça como Virtude...», op. cit., p. 24.

91 Cunha, P. Ferreira DA, Retbinking Natural Law..., op. cit., p. 60. «Uno quizá podría hablar hoy de evoluciones en la familia iusnaturalista. Si se nos permite alguna decoración barroca, parece que puede haber una especie de 'Neo-Derecho Natural', o incluso de 'Iusnaturalismo post-moderno'. Personalmente preferiría un nuevo híbrido, 'Neo-Iusnaturalismo crítico'». Al respecto, y en el prefacio del libro del Prof. Cunha Repensar o Direito, Mário Bigotte Chorão señala textualmente que: «Es manifiesto, particularmente, que el Doctor Ferreira da Cunha, aunque no queriendo renegar del 'legado de los clásicos', con sus ingredientes realistas, personalistas e iusnaturalistas, reivindica, en todo caso, el distanciamiento de la 'ortodoxia clásica' y la aproximación a una 'clásica heterodoxia'», llegando a afirmar Bigotte Chorão que Repensar o Direito es un «volumen heterodoxo». Vid., Bigotte Chorão, Prefácio, en Cunha, P. Ferreira DA, Repensar o Direito, Imprensa Nacional - Casa da Moeda (INCM), Lisboa, 2013, p. 20.

92 Cunha, P. Ferreira DA, Rethinking Natural Law..., op. cit., p. 60. 


\section{Conclusiones}

Frente al tópico de que tradicionalmente el portugués no es dado a la especulación filosófica en el campo jurídico ${ }^{93}$, autores contemporáneos como Paulo Ferreira da Cunha o António Braz Teixeira ${ }^{94}$ nos advierten de las peculiaridades del pensamiento jurídico portugués:

Ferreira da Cunha ${ }^{95}$, incide en la variedad de sus formas de expresión ${ }^{96}$, en que históricamente no se produjo una ruptura brusca entre iusnaturalismo clásico y iusracionalismo portugués ${ }^{97}$ en el siglo XVIII, o en la menor influencia del krausismo en Portugal de la que tuvo en España e Hispanoamérica ${ }^{98}$.

Teixeira, por su parte, apunta a la importancia de las ideas de libertad y de Justicia como constantes en el pensamiento jurídico portugués, a la atención de éste a lo concreto y a lo singular, y a la importancia atribuida por la reflexión iusfilosófica lusa a la noción de situación, a la historicidad y al tiempo humano ${ }^{99}$.

En este contexto, hemos visto cómo al menos desde que Cabral de Mocada, en la década de los cuarenta del pasado siglo comenzó a apartarse del

93 Cabral de Moncada, con cierta dosis de ironía escribía que «en cierto modo, si, como dijo un día Ortega, todo alemán lleva en sí un pequeño Kant, puede igualmente decirse que todo portugués, si lo aislaran del resto del mundo filosófico europeo, lleva en sí, incluso sin saberlo, un pequeño Santo Tomás de Aquino». Vid., Moncada, L. Cabral DE, Subsídios..., op. cit., p. 290.

94 Vid., TeiXeria, A. B., Caminhos e Figuras..., op. cit., p. 9.

95 Cunha, P. Ferreira DA, Filosofia do Direito..., op. cit., pp. 352-355. Afirma que «la gran constante en la mayoría de los escritores de esta corriente parece ser la preocupación por la Justicia, la defensa no siempre explícitamente iusnaturalista, de un pluralismo jurídico superador del positivismo jurídico; la búsqueda de la identidad jurídica nacional, la enfatización de la importancia de la caridad, de la misericordia y del perdón en el Derecho; y hasta la propuesta revolucionaria de abolición, no solo de la pena de muerte (Portugal fue el primer país en suprimirla), sino de todas las prisiones del alma y el cuerpo». Vid., también, CunHA, P. FERrEIRA DA, Temas e Perfis..., op. cit., p. 248.

96 Como el propio autor escribe, «El espíritu de la filosofía del derecho sopla donde quiere, y no hace acepción de géneros literarios, así podremos tener filosofía del derecho a través de un epigrama, de un proverbio, de una pieza de teatro... Y he ahí, de hecho, cómo el carácter denotativo de la filosofía del derecho (y de las ideas sobre la Justicia) se nos aparece más claramente». Cunha, P. Ferreira da, Filosofia do Direito..., op. cit., p. 402.

97 Cunha, P. Ferreira Da, Filosofia do Direito..., op. cit., p. 322. Rethinking Natural Law..., op. cit., pp. 29-34. Temas e Perfis..., op. cit., p. 137 y ss., al analizar el pensamiento político-jurídico de Ribeiro dos Santos versus el de Melo Freire en el setecientos portugués.

98 Cunha, P. Ferreira da, Temas e Perfis..., op. cit., pp. 213 y ss. Moncada, L. Cabral de, Subsídios..., op. cit., p. 171. En el mismo sentido, LaCASTa ZaBALZA, Cultura y Gramática..., op. cit., p. 364. En contra, TeixeIRA, A.B., Apresentação en Subsídios..., op. cit., p. 9.

99 Teixeira, A.B., O Pensamento..., op. cit., pp. 146 y 147. 
positivismo legalista, del sociologismo y del normativismo, la preocupación por la Justicia ha sido una constante en la filosofía jurídica portuguesa. Y lo fue para el existencialismo de Brandão o Santos, para el personalismo axiológico de un Castanheira Neves, o desde posturas más afines al iusnaturalismo clásico (aristotélico-tomista) como las del realismo jurídico clásico que representa aún Mário Bigotte Chorão. Este hilo conductor -la Justicia y su diverso papel con relación al derecho- es retomado con brío y nuevas perspectivas en la obra de Paulo Ferreira da Cunha, para quien la Justicia constituye el centro de su más o menos ortodoxa reflexión jurídica.

En suma, la relación entre el derecho y la Justicia, incluso consideradas como realidades interdependientes, así como el estrecho vínculo entre estas dos realidades y las concepciones antropológicas de las que parten los diversos pensadores ${ }^{100}$ son tópicos de la actual filosofía del derecho portuguesa. Quizá por ello Cabral de Moncada escribió que la filosofía tomista constituye en Portugal una especie de «filosofía popular», una constante de la consciencia portuguesa $^{101}$ a la que siempre se acaba por volver. Posiblemente, añadimos ahora nosotros sin el tinte peyorativo que Moncada daba a sus palabras, es por ello que aún perdura en el país vecino el estudio de la Justicia y su relación con el derecho.

Y es que, como escribiera Paulo Ferreira da Cunha, el siglo XXI será el siglo de Antígona o no será. Al menos que escoja ser el siglo de Creonte... ${ }^{102}$.

\footnotetext{
100 GÓMEZ GARCÍA, J.A., «Visión panorámica...», op. cit., p. 308.

101 MonCADA, L. CABRAL DE, Subsidios..., op. cit., p. 292. Se trata para Moncada de «un fuerte núcleo central, macizo, de filosofía escolástica y neo-escolástica, sobre todo tomista (...) dentro de la cual todavía, debe decirse, no deja de haber algo de disperso y donde no siempre todo está tan renovado como pudiera pensarse». Idem.

102 Cunha, P. Ferreira Da, Filosofia do Direito..., op. cit., p. 459.
} 
